WORKING PAPER NO 19

\title{
REGULATING FINANCIAL CONGLOMERATES
}

\section{Xavier Freixas Gyöngyi Lóránth \\ \& Alan D. Morrison}

The Working Paper is intended as a means whereby researchers' thoughts and findings may be communicated to interested readers for their comments. The paper should be considered preliminary in nature and may require substantial revision. Accordingly, a Working Paper should not be quoted nor the data referred to without the written consent of the author. All rights reserved.

(c) 2005 Xavier Freixas, Gyöngyi Lóránth \& Alan D. Morrison

Comments and suggestions would be welcomed by the authors.

e-mail: g.loranth@jims.cam.ac.uk 


\title{
Regulating Financial Conglomerates*
}

\author{
Xavier Freixas \\ Universitat Pompeu Fabra \\ and CEPR
}

\author{
Gyöngyi Lóránth \\ Judge Institute of Management, \\ University of Cambridge \\ and CEPR
}

\author{
Alan D. Morrison \\ Saïd Business School, \\ University of Oxford \\ and CEPR
}

March, 2005

\footnotetext{
${ }^{*}$ We are grateful to Hyun Shin for a number of stimulating discussions at an early stage in this project. We thank seminar participants at the National Bank of Belgium and at the Saïd Business School for comments. Generous financial support was provided by the Cambridge Endowment for Financial Research (CERF).

Correspondence address: Xavier Freixas, Universitat Pompeu Fabra, Department of Economics and Business, Jaume I building, Ramon Trias Fargas 25-17, 08005-Barcelona, Spain. email: xavier.freixas@econ.upf.es. Gyöngyi Lóránth, Judge Institute of Management, Trumpington Street, Cambridge CB2 1AG, UK. email: g.loranth@jims.cam.ac.uk. Alan Morrison, Merton College, Oxford OX1 4JD, UK. email: alan.morrison@sbs.ox.ac.uk.
} 


\title{
Regulating Financial Conglomerates
}

\begin{abstract}
We investigate the optimal regulation of financial conglomerates which combine a bank and a non-bank financial institution. The conglomerate's risk-taking incentives depend upon the level of market discipline it faces, which in turn is determined by the conglomerate's liability strucure. We examine optimal capital requirements for standalone institutions, for integrated financial conglomerates, and for financial conglomerates that are structured as holding companies. For a given risk profile, integrated conglomerates have a lower probability of failure than either their standalone or decentralised equivalent. However, when risk profiles are endogenously selected conglomeration may extend the reach of the deposit insurance safety net and hence provide incentives for increased risk-taking. As a result, integrated conglomerates may optimally attract higher capital requirements. In contrast, decentralised conglomerates are able to hold assets in the socially most efficient place. Their optimal capital requirements encourage this. Hence, the practice of "regulatory arbitrage", or of transfering assets from one balance sheet to another, is welfare-increasing. We discuss the policy implications of our finding in the context not only of the present debate on the regulation of financial conglomerates but also in the light of existing US bank holding company regulation.

KEY WORDS: Financial conglomerate, capital regulation, regulatory arbitrage.

JEL Classification: G21, G22, G28.
\end{abstract}




\section{Introduction}

The emergence of financial conglomerates is one of the major financial developments of recent years. ${ }^{1}$ Financial conglomerates are institutions which provide under a single corporate umbrella banking, insurance and other financial products. Conglomeration has been motivated by cost advantages from economies of scale and scope in insurance sales and securities underwriting, and by the perceived advantages of risk diversification. ${ }^{2}$ In this paper, we examine the optimal capital regulation of financial conglomerates.

We analyse the extent to which risk-taking incentives in conglomerates and their optimal capital regulation are affected by organizational form. Dierick (2004) and Shull and White (1998) discuss the effect of the different legal structures available to conglomerates. Although the choice of legal structure may be restricted by regulation, ${ }^{3}$ it is essentially a choice between structuring the conglomerate as an integrated entity subject to a unique liability constraint, or structuring it as a holding company and allowing its various divisions to fail independently. For example, universal banks are structured as integrated entities and carry on the same activities as bank holding companies. The conglomerate's capital regulation is constrained by its organizational form. Integrated entities face a single capital requirement, while the regulator can set separate capital requirements for each division of a decentralized conglomerate.

Integrated conglomerates achieve inter-divisional diversification (see Malkönen, 2004, and Allen and Jagtiani, 2000). Practitioners have argued conglomerate diversification will reduce bankruptcy risk and therefore that it should be rewarded with reduced capital requirements (see Oliver, Wyman \& Co., 2001). Although perfectly correct, this argument, and the empirical work upon which it rests, ignores entirely the fact that financial institutions select the riskiness of their portfolios in response to their institutional environment.

The process of transferring assets between conglomerate divisions in order to avoid high capital charges is popularly referred to as regulatory, or capital, arbitrage. Regulators usually regard capital arbitrage as a risk of conglomeration: see for example Dierick (2004). The Joint Forum (2001) provide an extensive discussion of regulatory arbitrage and are ambivalent as to its effects, concluding that it must be accompanied by evidence of adequate risk management practices. ${ }^{4}$ In fact, we show that capital arbitrage increases welfare by increasing market discipline. This effect

\footnotetext{
${ }^{1}$ The November 1999 Gramm-Leach-Bliley Act dismantled legal barriers to the integration of financial services firms which had been erected by the 1933 passage of the Glass-Stegall Act. Its passage made conglomeration legal in the United States. The Gramm-Leach-Bliley act was a response to market forces which had already resulted in the Federal Reserve Board's approval in 1998 of the merger of Citicorp and Travelers. Conglomeration in Europe, which was subject to fewer regulatory hurdles, followed the same trend: between 1985 and 1999 the value of merger and acquisition deals involving a commercial bank and an insurance company was $\$ 89.6$ billion, or $11.6 \%$ of all acquisitions by European financial institutions. See Lown, Osler, Strahan, and Sufi (2000) for detailed discussion about, and statistics concerning, the development of the European bancassurance market. A detailed discussion of conglomeration experience in the Benelux countries is provided by the National Bank of Belgium (2002).

${ }^{2}$ For a detailed discussion for the rationale behind conglomeration, see Berger, DeYoung, Genay, and Udell (2000), Milbourn, Boot, and Thakor (1999) and Dierick (2004). Santos (1998) discusses mergers between banks and insurance firms.

${ }^{3}$ Within Europe, it is illegal to combine insurance with banking, securities or any other commercial business in the same legal entity (Dierick, 2004, p. 17: see Article 6(1)(b) of the Life Asssurance Directive and Article 81(b) of the Non-Life Assurance Directive).

${ }^{4}$ Loss transfer from a sound conglomerate division to a divison close to financial distress is a distinct issue which regulators can deal with, subject to the passage of the necessary legislation.
} 
is further strengthened to the extent that insurance companies have a lower social cost of failure than banks.

The intuition for our results is as follows. Capital requirements force financial institutions to internalise costs which they would otherwise ignore. They should therefore reflect the fact that risk levels are selected endogenously. Banks have privileged access to deposit insurance, whose risk insensitive price biases them towards socially excessive risk-taking. Since this reduces the effectiveness of market discipline for banks, the appropriate response is to raise the capital requirement to which they are subject. In contrast, institutions such as insurance companies which are financed entirely by investors who charge a fair price for the risk to which they are exposed are subject to greater market discipline, and hence can be given a lower regulatory capital charge. In summary, pillar one (capital requirements) and pillar three (market discipline) of the new Basle Accord are substitutes.

In an integrated conglomerate, part of the funding is provided by risk-insensitive insured depositors. This reduces market discipline relative to a standalone non-bank institution. Depending upon the benefits derived from diversification, this reduction in market discipline may even justify higher capital requirements for the conglomerate than for its stand alone constituents. In contrast, each division of a holding company is subject to a locally efficient level of capital. If regulatory arbitrage is permitted, capital requirements can be set so as to induce the holding company to select and to allocate projects efficiently.

We develop this argument in a model in which banks differ from other financial institutions in two ways. First, their assets are opaque, which makes it impossible to assess the extent of their risk; second, their liability holders are unsophisticated small depositors who not only have limited ability and incentives to assess the financial state of their bank, but also are largely covered by a deposit insurance safety net. We also assume that there is a social cost of financial institution failure. The costs of these effects are ignored by bank shareholders and hence result in overinvestment in risky projects. The role of capital requirements is to force shareholders (and hence managers) to internalize these effects. This comes at a price: as in Myers and Majluf (1984) and Bolton and Freixas (2000), we assume that capital is exogenously costly as a result of informational frictions. Managers therefore react to capital requirements by raising their hurdle rate for new investments. The optimal capital requirement trades off these over- and under- investment effects.

In our framework, market financed institutions such as insurance companies are subject to market discipline. As a result they do not overinvest and hence it is socially optimal to impose a zero capital requirement since this will cause them to take socially optimal investment decisions. In contrast, deposit insurance premia do not fully reflect the bank's risk position. ${ }^{5}$ As a result their cost of funds is risk-insensitive. Capital requirements force them to account for the social costs of deposit insurance and hence they face a positive capital requirement.

We analyze decentralized, or holding company, and integrated conglomerates, consisting of a bank and a market-financed institution such as an insurance company. We assume that there are no informational or agency problems within a conglomerate, which aims simply to maximize its total value. As a result, the conglomerate will be indifferent as to where positive NPV projects are

\footnotetext{
${ }^{5}$ See Barth, Caprio, and Levine (2001) for evidence of flat deposit insurance rates around the world.
} 
held.

With the above assumption, we show that the social first best can be achieved in holding company conglomerates by setting a capital requirement of zero for the market-financed division, and setting very high capital requirements for the bank. In this case, the bank avoids its high cost of capital by transferring its assets to the market-financed division, which will accept all positive net present value investments.

The transfer of assets corresponds precisely to regulatory arbitrage. Hence, in contrast with commonly received opinion, regulatory arbitrage in our model has three unambiguously positive effects. First, the investment distortions induced by the deposit insurance fund will no longer occur. Second, marginal projects in which the standalone bank would not invest will now attract funds, because of the lower capital requirement. Third, assets are transferred to an institution with lower social costs of failure. Regulatory arbitrage therefore reduces the extent of the safety net and, by allowing for a more efficient use of capital, results in a greater degree of bank credit extension.

Under an integrated structure, the various operating units of the conglomerate are compelled to bail one another out. Losses in one division may therefore be covered by profits in another. However, in integrated conglomerates the effects of market discipline are attenuated by the extension of the deposit insurance safety net to the entire institution. As a result, we show that whenever possible, the conglomerate will assume so much risk that the failure of one division will result in the insolvency of the entire conglomerate. Integrated conglomerates may therefore open new channels for financial contagion. In contrast to the diversification hypothesis advanced above, we show that, for certain parameter values, integrated conglomerates may require a capital requirement which exceeds the sum of the constituent standalone division requirements.

Although we derive our results in a simple framework in which each institution effectively manages a single scaleable project, we believe that our intuition is robust to alternative set-ups. For example, a reasonable alternative framework would be one in which risk-averse bankers selected their investment portfolios according to the Capital Asset Pricing Model (see Hart and Jaffee, 1974).

Our work demonstrates that the diversification benefits of financial conglomeration may be overturned simply by allowing for the endogeneity of risk levels in financial institutions. A similar point is made by Boot and Schmeits (2000), in a model of conglomeration without deposit insurance. In their paper, market discipline is reduced because diversification reduces the sensitivity of aggregrate cashflows to divisional investment decisions. Unlike us, Boot and Schmeits are not concerned with capital regulation.

We conclude from the above discussion that, contrary to the majority view, holding company conglomerates allow for a more efficient allocation of resources than integrated ones. Our analysis is therefore supportive of existing legislative restrictions upon the integration of banking and insurance activities (see footnote 3), provided capital arbitrage is permitted.

In section 2 we present a model of standalone financial intermediaries and derive optimal capital requirements. Section 3 extends our analysis to holding-company and integrated conglomerates. Section 4 discusses the robustness of our results. Section 5 discusses the implications of our results for regulatory policy and section 6 concludes. 


\section{Standalone Financial Intermediaries}

In this section we analyze a one period interaction between a regulator, a financial intermediary, and the investors in the intermediary. The game which we study is illustrated in figure 1 . At time 0 the regulator sets a capital requirement $C$. At time 1 nature presents a project to the intermediary which requires an investment of $\$ 1$ and which has expected return $R$, where $R$ is drawn from $\left[R_{l}, R_{h}\right]$ according to the uniform distribution. We write $\Delta \equiv R_{h}-R_{l}$. The intermediary decides at time 2 whether or not to invest. If investment occurs, he must select the riskiness $B \in\{0, \bar{B}\}$ of the project. If the intermediary selects $B=\bar{B}$ then we say that he is "playing risky;" otherwise, we will say that he is "playing safe." Projects return $R+B$ or $R-B$, each with probability $\frac{1}{2}$. If the intermediary decides to invest then he must raise the $\$ 1$ investment at time 3. He raises $\$ C$ of capital and $\$(1-C)$ from investors. At time 4 the project's returns realize and are distributed to the investors.

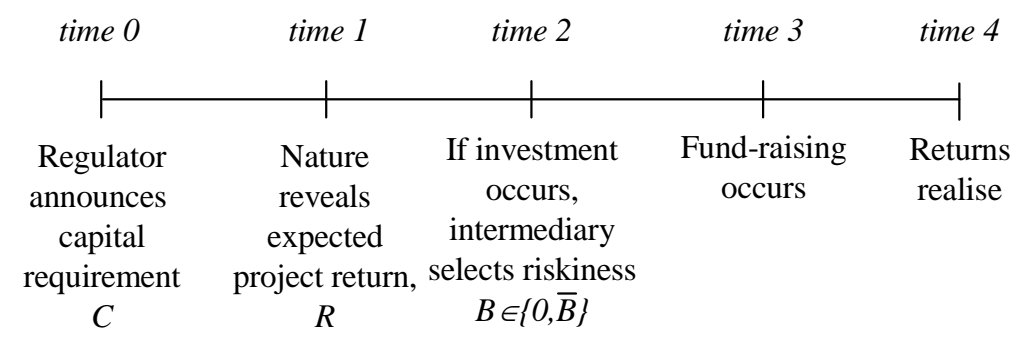

Figure 1: Time line for the operation of the standalone intermediary.

We assume that outside capital has an exogenous cost. This is in line with statements by practitioners and can be justified with respect to signalling stories à la Myers and Majluf. Specifically, we assume that the cost to the intermediary of raising an amount $C$ of capital is $C \kappa$ for some $\kappa>0$. Since $\kappa$ is a pure wealth transfer it will not feature directly in our welfare calculations, although it will have an indirect impact upon welfare through its impact upon investment incentives.

We consider two types of financial intermediaries: Deposit-Financed Intermediaries, which we will also refer to as DFIs or as banks; and Market-Financed Intermediaries, or MFIs. The MFIs within financial conglomerates are either insurance or securities firms. Financial intermediaries are subject to regulation which attempts to maximise the expected present value of investments, net of the social costs of failure. Regulators therefore ignore wealth transfers. They set capital requirements and, when appropriate, provide deposit insurance. They are constrained to base regulations upon hard data which are verifable by the courts. In particular, we assume that this means that the risk measurements used by the regulator are coarser than those available to an informed investor, who can base her investment decisions upon soft as well as hard information. As a result, depository institutions have privileged access to risk-insensitive funds. For the sake of simplicity we abstract from the details and assume that deposit insurance premia are zero. Any flat but non-zero deposit insurance premium would complicate our presentation without materially affecting our results.

The investors in banks, to whom we refer as depositors, are protected by a deposit insurance 
fund which will make good any losses which they experience. As a result their willingness to invest is independent of their bank's investment choices. The investors in MFIs do not have deposit insurance and so condition their willingness to pay upon the riskiness of their intermediary's investment choices. For convenience we will sometimes refer to MFI investors as bond-holders.

All of the players in our model are risk neutral.

We assume that the intermediary has a private $\operatorname{cost} \zeta \geq 0$ of bankruptcy. We interpret $\zeta$ as representing the intermediary's charter value: it is clearly a function of policy choices such as competition levels, but in our model we leave it as an exogenous variable. Finally, we assume that intermediary failure has a social cost $\phi>0$. When the intermediary is a bank, $\phi$ includes such exogenous factors as the impact of the bank's failure upon the payment system, and the costs of destroying informational assets which have a value in the relationship with the bank's clients. ${ }^{6}$ We assume that the social failure cost $\phi$ includes any social effects which the intermediary cares about. Hence we include $\phi$ in our welfare calculations, but not $\zeta$.

We define a fragile intermediary to be one which with non-zero probability will fail and we say that such an intermediary is assuming systemic risk. A sound intermediary is one which will never fail. The decision to run a fragile intermediary is endogenous.

We now compute the respective optimal capital requirements $C_{M}^{*}$ and $C_{D}^{*}$ for market- and deposit- financed intermediaries.

\subsection{Market-Financed Intermediaries}

To determine the optimal time 0 capital requirement $C_{M}^{*}$ for a MFI, we solve our model by backward induction, starting with the MFI's time 2 investment decision.

Firstly, we characterize the contract which the MFI writes with its bond-holders. Let $\rho$ be the quantity which the MFI promises to repay them. The bond-holders have priority in the event of project failure and we assume that there are no costs of bankruptcy.

Suppose that the regulator has set a capital requirement $C$. The intermediary will be fragile precisely when condition (1) is satisfied, so that it will fail in the event that the project returns $R-B:$

$$
R-B<\rho .
$$

Recall that $B$ is a choice variable and hence that fragility is an endogenous intermediary characteristic.

We assume that at time 3 , the bond-holders are able perfectly to observe both $R$ and $B$. Since they are risk-neutral it follows that the MFI's promised payment $\rho$ must satisfy

$$
\rho=\rho_{S} \equiv 1-C
$$

when the intermediary is sound, and $\frac{1}{2} \rho+\frac{1}{2}(R-\bar{B})=1-C$, or

$$
\rho=\rho_{F} \equiv 2(1-C)-R+\bar{B}
$$

\footnotetext{
${ }^{6}$ See James (1991) for an estimation of the cost of bank failure, and Slovin, Sushka, and Polonchek (1993) for the estimation of the cost of Continental Illinois bankruptcy to its clients.
} 
when the intermediary is fragile.

The expected profit of a sound MFI is

$$
\pi_{S}(C) \equiv \frac{1}{2}\left(R+B-\rho_{S}\right)+\frac{1}{2}\left(R-B-\rho_{S}\right)-C(1+\kappa)=R-(1+C \kappa),
$$

which yields the following individual rationality constraint for sound MFIs:

$$
R \geq R_{S}(C) \equiv 1+C \kappa
$$

The expected profit of a fragile MFI is

$$
\begin{aligned}
\pi_{M, F}(C) & \equiv \frac{1}{2}\left(R+B-\rho_{F}\right)+\frac{1}{2} \zeta-C(1+\kappa) \\
& =R-(1+C \kappa)-\frac{1}{2} \zeta .
\end{aligned}
$$

Since $\pi_{M, F}<\pi_{M, S}$ it follows immediately that the MFI will never choose to be fragile. This observation follows immediately from the second Modigliani-Miller proposition (1958): provided perfectly informed debt holders are able precisely to price the debt, the effect of additional risk taking by the manager is completely reflected in the additional cost of debt. Consequently, additional risk-taking cannot transfer wealth from debt to equity holders.

Notice that the strict inequality $\left(\pi_{M, F}<\pi_{M, S}\right)$ obtains because the manager faces a private cost of bankruptcy. We justify this cost with reference to managerial loss of reputation in the event of bankruptcy. We do not explore here the alternative possibility that the manager might be induced to take risks by his compensation schedule. When debt-holders can correctly price risk such a schedule, based for example upon stock options, would in any case be suboptimal.

The MFI will therefore select any investment whose return exceeds $R_{S}(C)$. Figure 2 illustrates the standalone MFI's investment choices as a function of $C$ and $R$ : for a given $C$, the MFI will accept any investment with expected return in excess of $1+C \kappa$, and will select $B$ so as to ensure that the intermediary is sound, as indicated on the figure by the script $\mathcal{S}$.

Proposition 1, whose proof is immediate from figure 2, states that market discipline will induce market-financed intermediaries to adopt a first-best investment strategy in the absence of capital regulation.

Proposition 1 When capital is set in accordance with equation (3) the intermediary accepts all projects for which $R \geq 1$ and is always sound.

$$
C_{M}^{*}=0
$$

\subsection{Deposit-Financed Intermediaries}

In this section we examine the optimal capital regulation of a deposit-financed intermediary. As discussed above, the risk measurements which the regulator can use in setting capital requirements are coarser than those which the bond-holders in a MFI use when establishing a fair price for their investments. We incorporate this requirement into our model by assuming that capital requirements can distinguish only between investment and non-investment. In the latter case the depositors' 


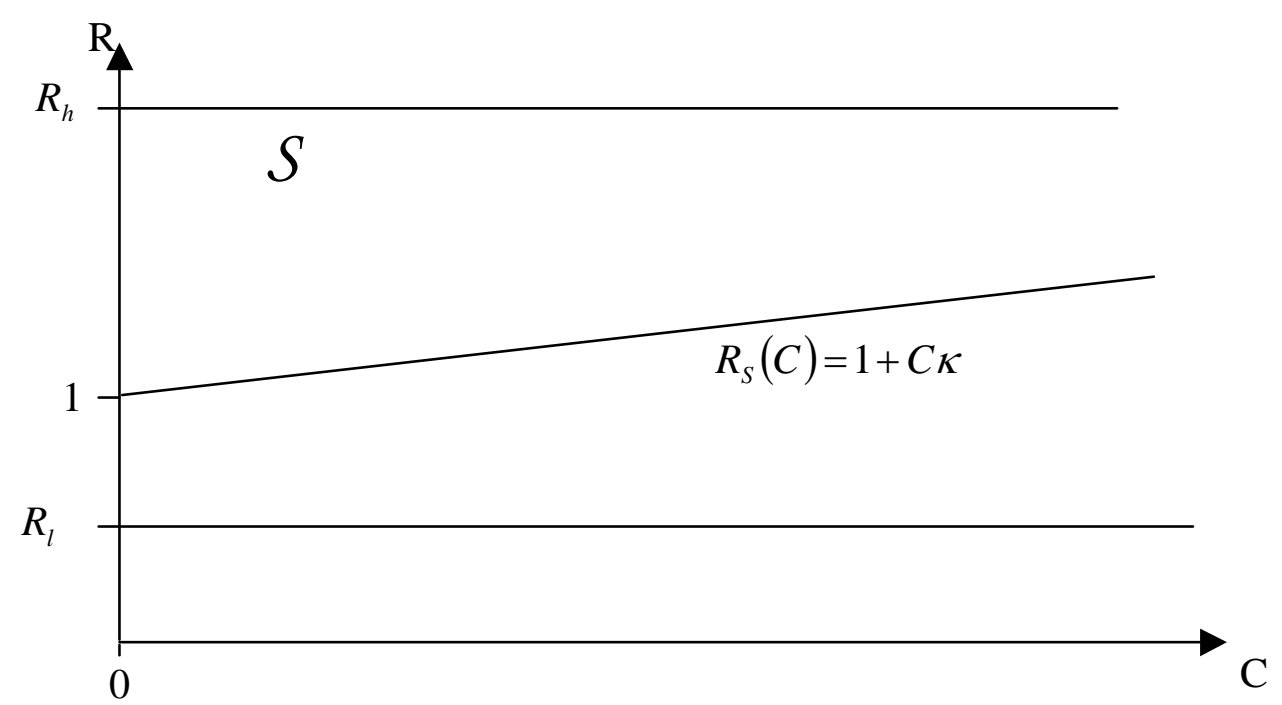

Figure 2: Investment choices for a standalone market-financed intermediary.

funds are entirely cash-collateralised and it is clearly optimal to set the capital requirement equal to zero. In the former case the banker could make any investment in $\left[R_{l}, R_{h}\right] \times\{0, \bar{B}\}$ and so the capital requirement in our model is risk-insensitive. We do not think that our qualitative findings would be affected if the regulator could use a finer partition of the investment space provided it remained coarser than that used by the market, but introducing such a partition into our model would involve needless complexity.

Note that, because the DFI's depositors are protected by deposit insurance, the DFI need only promise to repay $1-C$. A bank is therefore fragile precisely when

$$
R-B<1-C,
$$

and is otherwise sound.

The expected return to a sound bank is again given by $\pi_{S}(C)$, and the sound banking IR constraint is therefore $R \geq R_{S}(C)$, as in equations (2) and (SIR).

The expected profit from running a fragile bank is

$$
\pi_{F}(C, R) \equiv \frac{1}{2}(R+\bar{B}-(1-C))-\frac{1}{2} \zeta-C(1+\kappa)=\frac{1}{2}(R+\bar{B}-\zeta-1-C(1+2 \kappa)),
$$

which yields the following individual rationality constraint for fragile banking:

$$
R \geq R_{F}(C) \equiv 1+\zeta-\bar{B}+C(1+2 \kappa) .
$$

The banker will prefer fragile to sound banking precisely when $\pi_{F}-\pi_{S}>0$ : equivalently, when

$$
R<\bar{B}+1-C-\zeta .
$$

Note that equation (6) implies equation (4) and hence it is both a necessary and a sufficient condition for the banker to run a fragile bank. In other words, whenever the bank prefers to invest in a risky project, it prefers investment to non-investment. 
The bank's choice is summarized in figure 3, which shows for different combinations of the expected project return $R$ and the regulator's choice of $C$ how the bank will resolve its moral hazard problem. For $(C, R)$ pairs below the lines labelled FIR and SIR the bank will choose not to invest. Above these lines, investment will occur. In region $\mathcal{F}$ the bank plays risky and is fragile. The bank is sound in region $\mathcal{S}^{7}$

The intuition behind this figure is straightforward. Since risk-taking is not reflected in the cost of funds, highly leveraged banks have a strong incentive to incur more risk. Nevertheless, if the bank is sufficiently fortunate to possess a project with a high expected return $R$, selecting the risky project $(B=\bar{B})$ jeopardizes the return: hence, for sufficiently high $R$, the banker will select the safe project $(B=0)$. The critical level of return above which safe projects are preferred is increasing in the bank's leverage (see equation 6 ).

As the bank receives an implicit subsidy from the deposit insurance fund, it has an incentive to invest even when confronted with project whose present value net of the total cost $1+C \kappa$ of investment is negative. Since the subsidy is decreasing in the bank's capital exposure $C$, there will be a point at which the subsidy is insufficient to compensate for the risk of capital loss: this is the point $\left(C=\frac{\bar{B}-\zeta}{1+\kappa}\right)$ in figure 3 at which SIR and FIR cross. For $C$ to the right of this point, investment occurs only in safe projects whose return exceeds the total cost of funds, $1+C \kappa$.

Our analysis of bank behaviour as a function of the capital requirement $C$ enables us to determine the optimal capital requirement.

The following proposition characterizes the optimal capital requirements for a standalone bank.

Proposition 2 When regulating a standalone bank the optimal capital requirement $C^{*}$ is given by

$$
C^{*}= \begin{cases}C_{F}^{*}, & \phi<\bar{\phi} ; \\ C_{S}^{*}, & \phi \geq \bar{\phi},\end{cases}
$$

where $C_{F}^{*}, C_{S}^{*}$ and $\bar{\phi}$ are given by equations (7), (8) and (9) respectively.

$$
\begin{array}{r}
C_{F}^{*} \equiv \frac{\bar{B}-\zeta}{1+2 \kappa}+\phi \frac{1+\kappa}{(1+2 \kappa)^{2}} ; \\
C_{S}^{*} \equiv \frac{\bar{B}-\zeta}{1+\kappa} ; \\
\bar{\phi} \equiv \frac{\kappa(1+2 \kappa)}{(1+\kappa)^{2}}(\bar{B}-\zeta) .
\end{array}
$$

In the case where $C^{*}=C_{F}^{*}$ the regulator chooses optimally to introduce financial fragility; in the case where $C^{*}=C_{S}^{*}$ the regulator sets capital at precisely the minimum level to wipe out systemic risk.

Proof. See the appendix.

The optimality of financial fragility is somewhat surprising. Setting capital at a sufficiently low level to encourage risk-shifting may actually increase welfare because the over-investment induced

\footnotetext{
${ }^{7}$ Note that for high values of $R$ playing safe is not a necessary condition for soundness.
} 


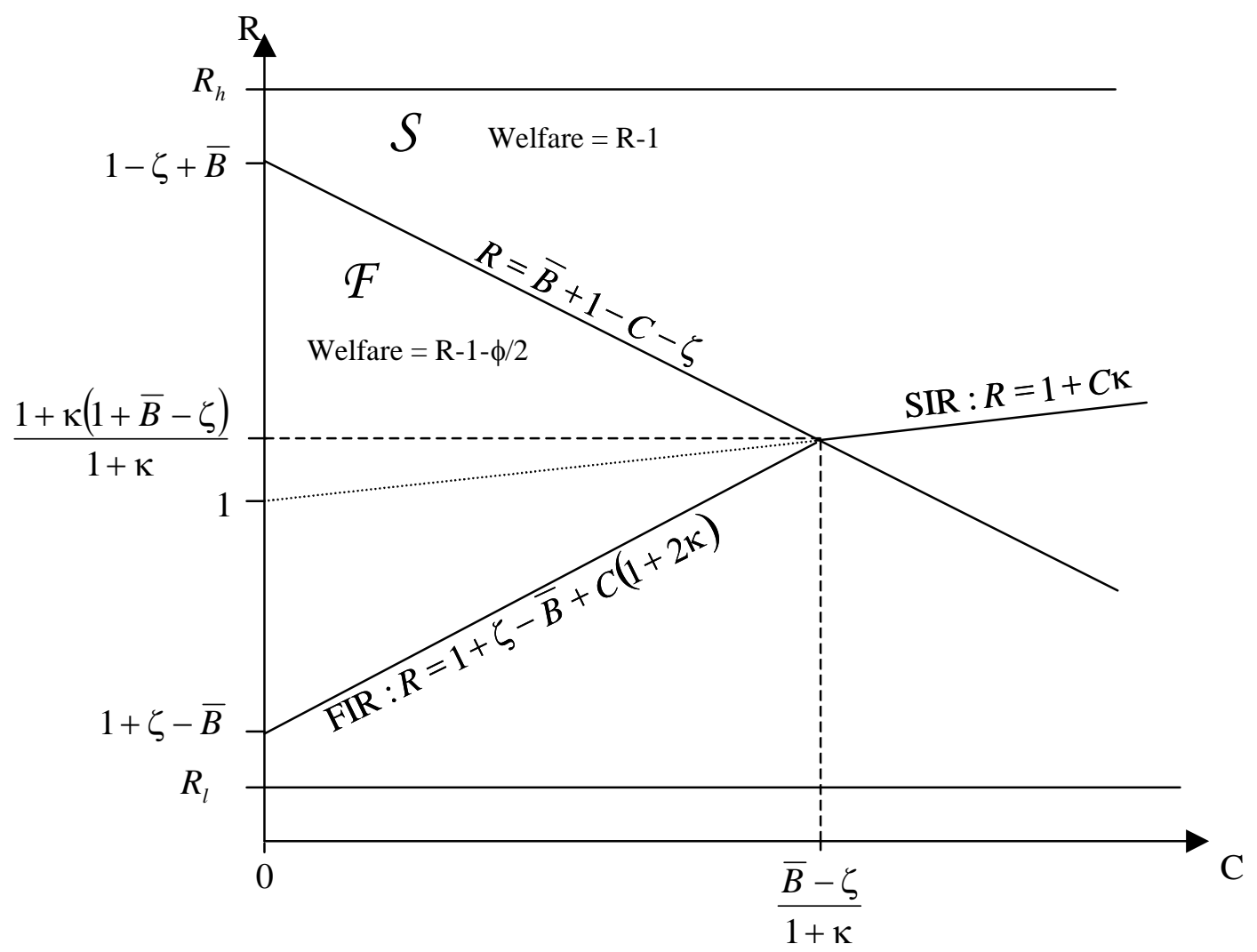

Figure 3: Stand alone banks: IR constraints and welfare.

by deposit insurance serves to counteract the under-investment associated with costly capital requirements. This effect outweighs the social costs of bank failure for sufficiently small $\phi$. In fact, we demonstrate in the appendix (equation (11)) that when $\phi=0$, the welfare $W_{F}$ with fragile banks is equal to the socially first best level. In this case, the capital requirement is optimally set so as ensure that over- and under- investment incentives cancel out and $R_{F}(C)=1$; for higher values of $\phi$, the marginal cost in terms of lost revenue from small increases beyond this level of the capital requirement are outweighed by the social benefit in terms of reduced bankruptcy probability and so the (constrained) optimal hurdle rate exceeds 1.

Finally, note that equations (7) and (8) imply that capital adequacy requirements and charter value $\zeta$ are substitutes. We discuss the relevance of this observation for competition policy in section 5 , which is devoted to policy implications.

\section{Financial Conglomerates}

We now analyze the optimal capital regulation of a financial conglomerate, which we define to be an intermediary which is created by combining an MFI with a DFI. We consider two types of conglomerate: holding-company conglomerates, and integrated conglomerates. Holding-company conglomerates consist of a separately capitalized DFI and MFI, both owned by an umbrella corporation. Hence the capital requirements for the DFI and the MFI in a holding company conglomerate 
can be different and the two divisions of the conglomerate could fail independently of one another. Moreover, the two divisions of a holding company conglomerate could in principle trade projects with one another in order to take advantage of differences in their respective capital regimes. We refer to this type of trade as "regulatory arbitrage."

Integrated conglomerates consist of a DFI and an MFI with a single balance sheet. They therefore have a single regulatory capital requirement. The DFI and the MFI in an integrated conglomerate cannot fail independently. Hence, diversification effects in integrated conglomerates may serve to diminish the likelihood of failure and hence of the associated systemic costs. However, as we will show, under some circumstances integration may serve to widen the coverage of the deposit insurance safety net and hence to introduce socially costly risk-shifting in the conglomerate.

We assume that the conglomerate's charter value is again $\zeta$ and that the systemic cost of failure is $\phi$ per division. Note that this implies that the total systemic cost of conglomerate failure is $2 \phi$.

The game which we analyze is illustrated in figure 4 .

\begin{tabular}{|c|c|c|c|c|}
\hline time 0 & time 1 & time 2 & time 3 & time 4 \\
\hline $\begin{array}{c}\text { Regulator } \\
\text { announces } \\
\text { capital } \\
\text { requirement } \\
\quad \text { C }\end{array}$ & $\begin{array}{c}\text { Nature } \\
\text { reveals } \\
\text { expected } \\
\text { project return, } \\
R_{D}, R_{M}\end{array}$ & $\begin{array}{c}\text { If investment } \\
\text { occurs, } \\
\text { intermediary } \\
\text { selects riskiness } \\
B_{D}, B_{M} \in \overline{\{0, B\}}\end{array}$ & $\begin{array}{l}\text { Possible } \\
\text { opportunity } \\
\text { for trade. } \\
\text { Fund-raising } \\
\text { occurs. }\end{array}$ & $\begin{array}{l}\text { Returns } \\
\text { realise }\end{array}$ \\
\hline
\end{tabular}

Figure 4: Time line for conglomerates.

At time 0 the regulator announces the capital requirement $C$. At time 1 nature presents the DFI and the MFI with projects each of which requires an investment of $\$ 1$ and whose expected returns are $R_{D}$ and $R_{M}$ respectively: $R_{D}$ and $R_{M}$ are independent draws of a random variable $\tilde{R}$ which is uniformly distributed on $\left[R_{l}, R_{h}\right]$. At time 2 the conglomerate decides whether or not to invest in the projects, and selects their risk levels $B_{D}$ and $B_{M}$ as in section 2. At time 3 funds are raised, and a holding-company conglomerate has an opportunity for the MFI and the DFI to trade projects. Returns are realized and distributed at time 4 .

\subsection{Holding-Company Conglomerates}

In this section we determine the optimal capital requirements $C_{H D}^{*}$ and $C_{H M}^{*}$ for holding company conglomerate divisions. As in section 2.2 the regulator is constrained to condition capital requirements only upon verifiable data so that the optimal capital requirement will be 0 for a completely cash collateralized division, and will otherwise be risk-insensitive.

Without inter-division trade the conclusions of this section would be identical to those of sections 2.1 and 2.2. Our results are therefore driven by the effects of regulatory arbitrage. We assume that within the conglomerate there is perfect information and hence that inter-division trade is neither impaired by informational asymmetry, nor driven by profit/loss transfers across divisions. When 
one of the divisions sells its investment to the other, it does so for a price of $\$ 1^{8}$ and its investments are then cash-collateralised, in which case its capital requirement will be zero.

Suppose now that a DFI is presented with an expected return which is too low for it to retain, but which would be profitable for an MFI. The above argument implies that the DFI will accept the investment and will finance it entirely through deposit-taking. It will then sell the project to the MFI division for $\$ 1$. The DFI's depositors will then be entirely cash-collateralised so that its capital requirement will be satisfied. The MFI will finance its purchase of the project using capital $C_{H M}$ and bonds to the value $1-C_{H M}$.

Regulatory arbitrage will increase welfare if it serves to discourage financial fragility. Since only DFIs will ever choose to be fragile, the optimal capital regime will make it more attractive to play safe and then to sell projects to the MFI than to retain them and to play risky. With respective capital requirements $C_{H M}$ and $C_{H D}$ for the MFI and the DFI, this will be the case precisely when $\pi_{F}\left(C_{H D}\right)<\pi_{S}\left(C_{H M}\right)$, or

$$
C_{H D} \geq \frac{1}{1+2 \kappa}\left\{\bar{B}-\zeta+1-R_{l}+2 C_{H M} \kappa\right\} .
$$

When this condition is satisfied the DFI will invest in any project whose expected return exceeds $R_{S}\left(C_{H M}\right)$. It will always play safe and it will sell its project to the MFI.

Since the MFI will always be sound and will invest in any project whose return exceeds $1+$ $C_{H M}(1+\kappa)$, the following result is immediate:

Proposition 3 The respective optimal capital requirements for the market- and deposit- financed divisions of a holding-company financial conglomerate are as follows:

$$
\begin{array}{r}
C_{H M}^{*}=0 ; \\
C_{H D}^{*}=\frac{1}{1+2 \kappa}\left\{\bar{B}-\zeta+1-R_{l}\right\} .
\end{array}
$$

This will achieve the first-best outcome: both divisions will invest in any project for which $R \geq 1$ and both will be sound. The MFI will retain all of its projects; the DFI will sell its projects to the MFI.

Recall that with non-zero social costs $\phi$ of failure, the best we can do is deliberately to introduce some underinvestment, and when $\phi<\bar{\phi}$ also some fragility, into a standalone DFI. Proposition 3 therefore demonstrates that by achieving the first best, capital arbitrage in a decentralized conglomerate is welfare-improving. The intuition for our result follows from a proper understanding of the purpose of capital regulation: it is intended to force financial intermediaries to internalize the [it is not only systemic] costs of actions which they would otherwise ignore. When these actions are already internalized, as they are in the case of an MFI, further capital regulation serves only to impede the intermediary's efficient operation. Hence a regime which encourages the divisions of a holding company conglomerate to hold their investments in the division which suffers from the lowest systemic externalities will raise welfare.

\footnotetext{
${ }^{8}$ This is a statement about the division of surplus. It simplifies the algebra but is not necessary for our conclusions.
} 
This goes against the grain of many of the assumptions (implicit and explicit) in regulatory discussions. These tend to focus on concerns that conglomerates will use regulatory arbitrage to shift poor investments into DFIs and so transfer their expected losses to the deposit insurance fund. We have shown that this is only worth doing under a poorly designed capital adequacy regime. When capital requirements are set optimally, this type of regulatory arbitrage will cost more than it is worth. Capital requirements for holding-company DFIs are therefore set significantly above those for standalone DFIs precisely in order to encourage regulatory arbitrage.

Finally, we note that the prediction in proposition 3 that DFIs sell all of their loan assets is in reality rather extreme. Banks are sometimes prohibited by the terms of their customer agreements from selling their loans and hence would in practice retain some assets. Incorporating this requirement into out model might serve to reduce somewhat the optimal capital requirement $C_{H D}^{*}$, but it would not materially affect our results.

\subsection{Integrated Conglomerates}

Integrated conglomerates have a single balance sheet and so cannot engage in regulatory arbitrage. In an integrated conglomerate there is no particular reason in our model why any funds should be raised from depositors. There are however clear social reasons why deposit-taking will continue to occur and we therefore assume that the funds which the conglomerate needs for investment are raised in equal proportions from depositors and from bond-holders.

Integrated conglomerates can make two, one, or no investments. We start by analyzing the conglomerates with two investments. We define $\tilde{R} \equiv \tilde{R}_{M}+\tilde{R}_{D}$ to be the total expected return from the two projects which the conglomerate runs. Let

$$
\beta \equiv B_{M}+B_{D}
$$

be the total riskiness of the conglomerate. Then we consider three cases: $\beta=2 \bar{B}, \bar{B}, 0$, according to whether the conglomerate plays risky with two, one, or no projects. When $\beta=\bar{B}$ the conglomerate can return in a high or a low state, each with probability $\frac{1}{2}$ : in this case we will refer to the conglomerate as undiversified. When $\beta=2 \bar{B}$ we say that the conglomerate is diversified. Diversified conglomerates return high $(R+2 \bar{B})$, middle $(R)$ or low $(R-2 \bar{B})$ payouts with respective probabilities $\frac{1}{4}$, $\frac{1}{2}$, or $\frac{1}{4}$. In a diversified conglomerate the returns on a failing project may be cancelled by those on a successful one. However, in case of bankruptcy, a diversified institution may generate higher expected deposit insurance payouts than an undiversified conglomerate. This is because low state returns for diversified conglomerates $(R-2 \bar{B})$ are below those of undiversified conglomerates $(R-\bar{B})$, and this raises the threshold $R$ value below which the deposit insurance fund pays out.

We summarize the properties of integrated conglomerates in proposition 4 :

Proposition 4 Every integrated conglomerate with two investments is diversified and fragile $(\beta=$ $2 \bar{B})$ or risk-free $(\beta=0)$.

Proof. See the appendix. 


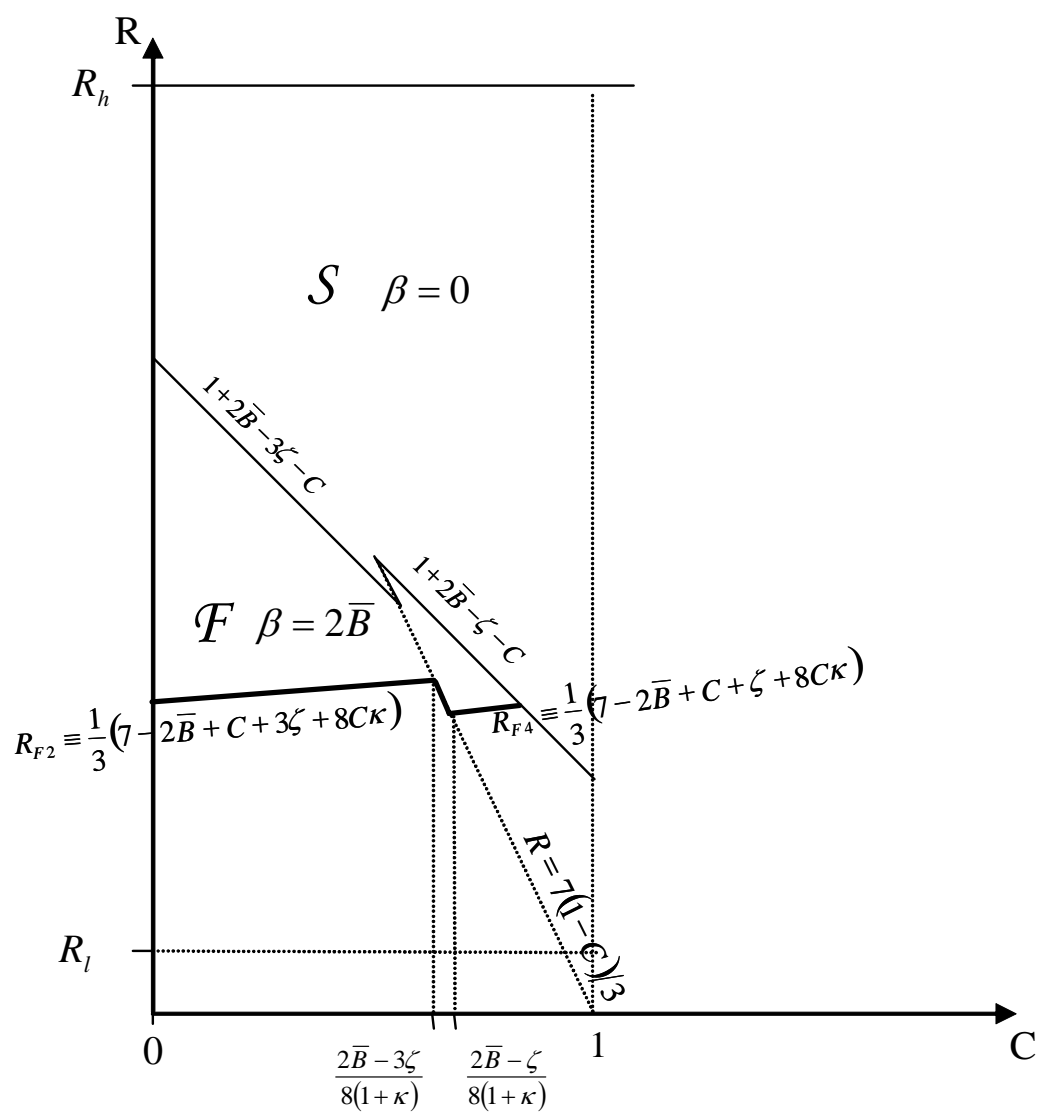

Figure 5: Consolidated conglomerate investment strategies. The manager's participation constraint is indicated by the bold line. In the region where $\beta=2 \bar{B}$ the conglomerate is diversified and it is fragile; below the line $R=7(1-C) / 3$ it fails when it returns $R$ or $R-2 \bar{B}$; above this line it fails when it returns $R-2 \bar{B}$. In the region $\beta=0$ the conglomerate is sound.

Proposition 4 is illustrated in figure 5, which shows the IR constraints for investment, and the sound and fragile regions. The choice between diversified and undiversified conglomerates is driven by a trade-off between deposit insurance safety net payments and the loss of charter value if the conglomerate defaults on its bond debt. We demonstrate in the appendix that in situations where charter value outweighs the benefits of deposit insurance payouts, the expected return from investment is too low to satisfy the manager's participation constraint.

Along the line $R=7(1-C) / 3$, figure 5 illustrates a discontinuity in the boundary between the fragile and sound regions. Below this line diversified conglomerates default on bonds in the middle and low states, while above it they default only in the low state. This affects the expected loss of charter value and explains the discontinuity.

The conglomerate plays safe $(\beta=0)$ when playing risky $(\beta=2 B)$ does not generate a sufficient deposit insurance payout to cover the expected loss of charter value.

Proposition 3 shows that first best levels of investment can be achieved without systemic risk in the holding company and so we have: 
COROLlaRY 1 From a welfare perspective, the holding company conglomerate structure weakly dominates the integrated structure.

In other words, once capital requirements are properly set, holding companies are a better way to structure conglomerates. This result clearly has important policy implications.

We now turn to a second, related question: should integrated financial conglomerates receive a lower regulatory capital allocation than standalone DFIs by virtue of their risk diversification? To answer this question we must consider both the diversification effect and also the possibility that integration might increase systemic risk by inducing additional risk-taking by the MFI. This latter possibility has never been properly considered in the debate on conglomerate regulation.

It is not a priori clear whether the diversification or the risk-shifting effects of integration dominate, although corollary 1 indicates that the best way to deal with the problem is to impose a holding-company structure upon financial conglomerates. The optimal capital requirement calculation for integrated financial conglomerates proves in our model to be intractable. To demonstrate that the risk-shifting effect can bite we provide a simple illustrative example in which any stand-alone institution would be sound, while an integrated conglomerate need not be.

Suppose that $\phi \geq \bar{\phi}$ so that (proposition 2) the optimal standalone capital requirement for a DFI would be $C_{S}^{*}$ and hence the DFI would always be sound. Note (proposition 1) that the MFI would hold optimal capital of 0 and that it would always be sound. Consider the investment choices of an integrated conglomerate whose total capital requirement is $0+C_{S}^{*}=C_{S}^{*}$. This reflects current legislation: the consensus amongst practitioners is that the diversified integrated conglomerate should attract a lower capital requirement. Note that in our formula the total capital requirement for the integrated conglomerate is $2 C$ and hence that in our example, $C=\frac{1}{2} C_{S}^{*}$.

Lemma 1 If $\phi \geq \bar{\phi}$ then precisely when $\bar{B}>\frac{2}{3}+\zeta$, there is a non-empty range of $R$ values for which a two project integrated conglomerate with capital requirement $\frac{1}{2} C_{S}^{*}$ will be diversified $(\beta=2 \bar{B})$ and fragile.

Proof. See the appendix.

For $\phi \geq \bar{\phi}$, separately capitalized conglomerate divisions would be sound; the MFI is always charged for its risk-bearing, and we proved in section 2 that with capital requirement $C_{S}^{*}$ the DFI will be unable to assume a sufficiently large risk to draw upon the deposit insurance fund. When the two institutions are integrated and take total risk $2 \bar{B}$, the conglomerate's bond-holders will continue to charge for the risk which they assume. However, for large enough $\bar{B}$, failure is sufficient to trigger a claim on the deposit insurance fund for which the conglomerate will make no marginal payment. When the expected value of the claim is sufficiently large to compensate for the expected loss of charter value the conglomerate will choose to be fragile.

This result illustrates our point: holding capital requirements constant as integrated conglomerates form can result in an increased probability of failure. Hence, contrary to received opinion in the market, when the systemic cost $\phi$ of failure is sufficiently large capital requirements for integrated conglomerates should exceed the sum of their component stand-alone requirements. 
Proposition 4 and lemma 1 discuss the properties of two project conglomerates. Lemma 2 ,guarantees their existence.

Lemma 2 Integrated conglomerates accept all positive NPV projects. They also accept some negative NPV projects.

Proof. See the appendix.

Lemma 2 proves that the fragile region of figure 5 is non-empty. Within this region integrated conglomerates take risks with two projects in order to generate an expected deposit insurance payout. If the conglomerate has a single project whose return falls within this region, it is worth accepting a small loss on a second, risky, project in exchange for the deposit insurance subsidy which it generates.

Note that the IR constraints are increasing in the charter value $\zeta$ and decreasing in project riskiness $\bar{B}$, while these parameters have the opposite effect upon the upper bound $1+2 \bar{B}-\zeta-C$. Hence:

Lemma 3 For a given capital requirement, the probability that an integrated conglomerate will fail is increasing in the maximum investment riskiness $\bar{B}$ and decreasing in the charter value $\zeta$.

As in previous sections it follows that $\zeta$, which may be interpreted as charter value, substitutes for financial capital.

\section{Extensions}

In this section we explore the robustness of our model by considering a number of possible extensions that result from relaxing some of our simplifying assumptions.

\subsection{Market Discipline}

Our formal analysis assumes perfect market discipline for the market financed institution and no discipline for the depository institution. We discuss relaxations of these assumptions below.

First, market monitoring is in practice costly with the consequence that monitoring incentives vanish for institutions which are in equilibrium sound. Hence a mixed strategy equilibrium in monitoring and gambling will emerge (Grossman and Stigltz, 1980). This attenuates the effects of market discipline. Our conclusions carry over, but the benefits of regulatory arbitrage are reduced.

Second, in practice more sophisticated regulation may induce information revelation by informed bankers. This is the goal of the internal models approach of the second Basle Accord (2004). To the extent that this is successful, it reduces the benefits of a holding company structure with regulatory arbitrage. Such arbitrage is at worst welfare neutral, however, and so our conclusions are (weakly) unaffected by this observation. 


\subsection{Costly Asset Transfers}

We assume in our model that transferring assets between divisions is costless. In practice, there may be costs: in particular, suppose that banks are endowed with monitoring skills which are absent in market-financed institutions (Diamond and Rajan, 2001). This introduces two costs, which must be weighed against the benefits of improved market discipline and potentially lower social costs of failure. Firstly, assets which are transferred will be less effectively monitored. Secondly, setting capital requirements sufficiently high to induce regulatory arbitrage will raise the hurdle rate for informationally opaque projects which it is not profitable to transfer. Both of these effects will serve to diminish the optimal capital requirement for depository institutions. The development of securitization techniques which allow for risk but not monitoring responsibility to be transferred will attenuate the effects examined in this paragraph.

\subsection{Social Costs of Failure}

Our analysis is predicated upon the assumption that the social cost $\phi$ of institutional failure is the same for deposit- and market-financed intermediaries. However, a number of authors have argued that the systemic costs of bank failure are significantly higher than those of insurance or security company failure: bank failure may give rise to contagion; bank failure affects the payments system; and bank failure may cause the loss of valuable informational assets. These effects serves to strengthen our conclusions. We have based our argument entirely upon the endogeneity of bank risk-taking and the risk-insensitivity of bank finance. However, our conclusion that a holding company structure is optimal when allowing for regulatory arbitrage could equally be derived in the absence of these effects, provided the social cost of bank failure exceeds that of market-financed institutions. With this assumption, as capital requirements force the internalisation of systemic externalities, they will optimally be higher for banks than for market-financed intermediaries. As a result, the bank's hurdle rate will exceed the market-financed intermediary's. Thus, regulatory arbitrage will again lower the effective cost of bank investment and hence will raise welfare.

\subsection{Bank Conglomerates}

We can use our approach to analyse related questions regarding conglomerate regulation. Of particular relevance are conglomerates formed from two banking divisions. Since the adoption of the Financial Institutions Reform, Recovery and Enforcement Act (FIRREA) in 1989, bank holding companies in the United States have been subject to the Federal Reserve's "source of strength" doctrine, which forces the holding company or another division within the holding to bear any costs incurred by the deposit insurance company in the wake of divisional failure. ${ }^{9}$ Any bank holding company that is unwilling or unable to bear the costs will be deemed "unsafe and unsound" and therefore the Federal Reserve Board will force its closure. This regulation was originally intended to discourage ex post loss concentration in distressed divisions in order to maximise the value of the deposit insurance option (see footnote 4).

\footnotetext{
${ }^{9}$ Ashcraft (2004) shows that in the US a bank affiliated with a multi-holding company is significantly safer than either a standalone bank or one affiliate with a one-bank holding.
} 
The source of strength doctrine prevents one bank division from walking away from the other in the event of its failure. Hence it forces integration in bank conglomerates. We have demonstrated that such forced integration would be socially sub-optimal in conglomerates containing a nonbank division, as it would prevent risk concentration in the division subject to the most market discipline and the lowest social failure cost. However, these effects are constant across the divisions of a bank conglomerate and hence the above argument does not apply. On the contrary, the source of strength legislation ensures that banks internalise as much as possible of the risk which they take. Notwithstanding this observation, a similar argument to that underlying proposition 4 implies that an integrated bank conglomerate may take more risk than any of its constituents would have done on a stand alone basis. The reason is that, when each division is able to bail out the others, a greater degree of risk is required to profit from the deposit insurance put option. If the source-ofstrength doctrine simply incentivises the holding company to take more risks then it generates no efficiency gains.

If instead liability were limited by the requirement that the failure of one division could not trigger the failure of the other, access to the deposit insurance net would be diminished, and with it risk-shifting incentives. This would clearly be desirable. Even with this alteration, though, the source of strength doctrine fails to account for the substitutability of capital regulation and market discipline (i.e., of pillars one and three of the new Basle Accord). We have argued that capital requirements should optimally counter the increased risk-shifting incentives engendered by deposit insurance. As a consequence, when these incentives are ameliorated, capital requirements should be reduced. Since a successful source of strength doctrine would reduce the value to a bank holding company of the deposit insurance put option, it would increase market discipline and hence reduce risk-shifting incentives. Hence, for source of strength legislation to increase efficiency it should be accompanied by correspondingly looser capital requirements. ${ }^{10}$

In summary, our framework indicates the potential for efficiency gains from source-of-strength type regulations, but also demonstrates that these gains are currently not fully realised for two reasons. First, a division may take larger risks so that its failure triggers the failure of the other and hence maintains its access to the deposit insurance put option. Second, to the extent that source-of-strength regulations succeed in increasing market discipline, they should be accompanied by a downward adjustment in capital requirements.

\section{Policy Implications}

\subsection{Level Playing Field}

Since capital is costly, an essential precursor to fair competition in the financial sector is that no institution should be placed at a relative disadvantage by capital regulation. This is the basis of the Basle Accord's emphasis upon a "level playing field" (see Basle Committee on Banking Supervision, 1997). A commonly deployed argument in favour of integrated conglomerates is that they reduce systemic risk by diversifying risks across banks and insurance companies. This observation has been used to argue that a level playing field will allocate lower capital requirements to an integrated

\footnotetext{
${ }^{10}$ A similar effect obtains in branch-organised multinational banks: see Lóránth and Morrison (2003).
} 
conglomerate than to either a holding company conglomerate, or the corresponding standalone institutions.

Provided asset riskiness is exogenous, this argument is perfectly correct. Our model highlights an additional effect that has received less attention: namely, that by extending the reach of the deposit insurance net to the conglomerate's MFI, integration may actually introduce additional risk-taking incentives and hence increase systemic risk. Lemma 1 demonstrates that for certain parameter values, the second of these effects dominates the first. When this happens, level playing fields actually require integrated conglomerate capital requirements to exceed those of the corresponding standalone institutions.

It has been acknowledged for some years that charter value forces banks to internalise their costs of failure and hence discourages excessive risk-taking. ${ }^{11}$ As a result of this effect, charter value and capital are substitutes (in our model, see propositions 2 and 3). Lemma 1 establishes a new effect: it demonstrates that optimal integrated conglomerate capital requirements exceed standalone requirements for sufficiently low charter value. In other words, diversification alone is not enough to reduce capital requirements.

\subsection{Pro-Cyclicality}

A frequently voiced criticism of the new Basle Accord on capital regulation is that it may serve to amplify the economic cycle. As far as we are aware, pro-cyclicality has not featured in discussions of financial conglomeration. In this section we suggest that it may be a concern in integrated conglomerates.

The most important MFIs in financial conglomerates are insurance companies, whose assets are market securities. As such, their investments have the same expected return as the market. In contrast, DFIs hold customer loans which have distinct return characteristics. ${ }^{12}$

In the light of the observations in the previous paragraph, we consider a variation of our model in which MFI returns are equal to those on the market and the DFI makes its investment decisions with a knowledge of the expected market return $R_{M}$. When the sum of $R_{M}$ and the expected DFI return lies in region $\mathcal{F}$ of figure 5 the integrated conglomerate will be fragile. For a given DFI return distribution, the probability that this occurs is clearly decreasing in $R_{M}$.

During an economic slowdown, the maximum investment riskiness $\bar{B}$ increases, bank charter value $\zeta$ decreases and the expected market return $R_{M}$ to MFI portfolios drops. Lemma 3 shows that the first two effects will cause an increase in the size of region $\mathcal{F}$ in figure 5 . This translates into an increased probability that the integrated conglomerate is fragile.

In summary, poor expected market returns increase the conglomerate's incentive to play risky and hence exacerbate systemic pressures already in the economy. The endogeneity of risk selection therefore reverses the standard assumption that diversification has a stabilizing effect in economic downturns. Conversely, the size of the fragile region is smaller for high expected market returns and the probability that the total conglomerate return lies within it is also reduced.

\footnotetext{
${ }^{11}$ The initial paper on this topic was Keeley (1990).

${ }^{12}$ Although loan portfolio returns are correlated with the market, there is some evidence that bank loans have less systematic risk than securities and insurance company portfolios: see Allen and Jagtiani (2000).
} 


\section{Conclusion}

In this paper we present a model of financial intermediation in which capital requirements serve to force shareholders to internalize failure and deposit insurance costs which they would otherwise ignore. Our basic intuition is that risk-taking incentives are endogenous and depend upon the extent to which a financial institution is subject to market discipline. When market discipline is weak, as in a depository institution whose depositors are protected by deposit insurance, the institution will tend to take socially excessive risks. In this case, regulatory capital requirements serve as a costly substitute for market discipline: optimal regulation trades off their costs against their disciplining effects. Hence, our results suggest that pillars one and three of the new Basle Accord are (partial) substitutes.

Integrated conglomerates are diversified and hence may better internalise the risks which they assume. However, they are partially financed by risk-insensitive deposits and this undermines the market discipline of their non-bank division, which may as a result assume larger risks. When the second effect out weighs the first, they will be relatively less efficient than the sum of their standalone parts, and they should be subject to a higher aggregate capital adequacy requirement.

In contrast, we find that the ability to set separate capital requirements for each of the divisions of a holding-company conglomerate allows the regulator to induce first-best investment behaviour by the conglomerate. This is because the regulator can set capital requirements to reflect the riskiness of each division and hence can encourage the conglomerate to hold assets in the most efficient location. Hence, our results rest upon the existence of regulatory arbitrage, which in our set-up is unambiguously welfare-increasing.

Although our formal analysis examines a conglomerate containing a bank and a non-bank institution, our framework allows us to comment upon the Federal Reserve's "source of strength" doctrine, which forces the holding company or another division within the holding to bear any costs incurred by the deposit insurance company in the wake of divisional failure. In line with our results on integrated conglomerates, we argue that this regulation may actually serve to increase bank risk-taking incentives. Moreover, to the extent that it succeeds in enhancing market discipline, it should be accompanied by reduced capital requirements.

Finally, we find that the incentive for excessive risk-taking in an integrated conglomerate is greatest when the total expected returns of its divisions is lowest. Hence, in bank and insurance conglomerates, to the extent that the insurance company portfolio tracks the market, the probability of risk-shifting is greatest in economic downturns. Hence, integrated conglomerates may invest so as to amplify the economic cycle.

\section{References}

Allen, L., and J. Jagtiani, 2000, "The Risk Effects of Combining Banking, Securities, and Insurance Activities," Journal of Economics and Business, 52, 485 - 497.

Ashcraft, A. B., 2004, "Are Bank Holding Companies a Source of Strength to Their Banking Subsidiaries?," Staff Report 189, Federal Reserve Bank of New York, NY. 
Barth, J. R., G. Caprio, Jr, and R. Levine, 2001, "The Regulation and Supervision of Banks Around the World: A New Database," Policy Research Working Paper 2588, World Bank, Washington, DC.

Basle Committee on Banking Supervision, 1997, "Core Principles for Effective Banking Supervision," Publication 30, Bank for International Settlements, Basle.

Basle Committee on Banking Supervision, 2003, "The New Basle Capital Accord," Consultative document, Bank for International Settlements, Basle.

Berger, A. N., R. DeYoung, H. Genay, and G. F. Udell, 2000, "Globalization of Financial Institutions: Evidence from Cross-Border Banking Performance," Brookings-Wharton Papers on Financial Services, 3.

Bolton, P., and X. Freixas, 2000, "Equity, Bonds and Bank Debt: Capital Structure and Financial Market Equilibrium under Asymmetric Information," Journal of Political Economy, 108, 324 351.

Boot, A. W. A., and A. Schmeits, 2000, "Market Discipline and Incentive Problems in Conglomerate Firms With Applications to Banking," Journal of Financial Intermediation, 9, 240 - 273.

Diamond, D. W., and R. G. Rajan, 2001, "Liquidity Risk, Liquidity Creation, and Financial Fragility: A Theory of Banking," Journal of Political Economy, 109, 287 - 327.

Dierick, F., 2004, "The Supervision of Mixed Financial Services Groups in Europe," Occasional Paper 20, European Central Bank, Frankfurt.

Grossman, S. J., and J. E. Stiglitz, 1980, "On the Impossibility of Informationally Efficient Markets," American Economic Review, 70, 393-403.

Hart, O. D., and D. M. Jaffee, 1974, "On the Application of Portfolio Theory to Depository Financial Intermediaries," Review of Economic Studies, 41, 129 - 147.

James, C., 1991, "The Losses Realised in Bank Failures," Journal of Finance, 46, 1223 - 1242.

Joint Forum, 2001, Risk Management Practices and Regulatory Capital: Cross-Sectoral Comparison, Bank for International Settlements, Basel.

Keeley, M., 1990, "Deposit Insurance, Risk, and Market Power in Banking," The American Economic Review, 80, 1183 - 1200.

Lóránth, G., and A. D. Morrison, 2003, "Multinational Bank Capital Regulation with Deposit Insurance and Diversification Effects," Working Paper 2003-FE-11, Oxford Financial Research Centre, University of Oxford.

Lown, C. S., C. L. Osler, P. E. Strahan, and A. Sufi, 2000, "The Changing Landscape of the Financial Services Industry: What Lies Ahead?," Federal Reserve Bank of New York Economic Policy Review, 6, 39 - 55 .

Mälkönen, V., 2004, "Capital Adequacy Regulations and Financial Conglomerates," Discussion Paper 10.2004, Bank of Finland, Helsinki.

Milbourn, T. T., A. W. A. Boot, and A. V. Thakor, 1999, "Megamergers and Expanded Scope: Theories of Bank Size and Activity Diversity," Journal of Banking and Finance, 23, 195 - 214. 
Modigliani, F., and M. H. Miller, 1958, "The Cost of Capital, Corporation Finance and the Theory of Investment," American Economic Review, 48, 261 - 297.

Myers, S., and N. Majluf, 1984, "Corporate Financing and Investment Decisions When Firms Have Information Investors Do Not Have," Journal of Financial Economics, 13, 187-222.

National Bank Of Belgium, 2002, "Financial Conglomerates," Financial Stability Review, 1, 61 80.

Oliver, Wyman \& Company, 2001, "Study on the Risk Profile and Capital Adequacy of Financial Conglomerates," Study commissioned by Dutch regulators (De Nederlandsche Bank, Pensioen\& Verzekeringskamer, Stichting Toezicht Effectenverkeer, Nederlandse Vereniging van Banken, Verbond van Verzekeraars).

Santos, J. A. C., 1998, "Commerical Banks in the Securities Business: A Review," Working Paper 56, Bank for International Settlements, Basle.

Shull, B., and L. J. White, 1998, "Of Firewalls and Subsidiaries: The Right Stuff for Expanded Bank Activities," Working Paper CLB-98-017, New York University Center for Law and Business, New York, NY.

Slovin, M. B., M. E. Sushka, and J. A. Polonchek, 1993, "The Value of Bank Durability: Borrowers as Bank Stakeholders," Journal of Finance, 48, 247 - 266.

\section{Appendix}

\section{Proof of Proposition 2}

Recall that welfare is defined to be the total surplus generated by the bank, net of any social costs. Hence, a sound bank generates welfare $R-1$ and a fragile one generates welfare $R-1-\frac{\phi}{2}$. The regulator's job is to select $C$ so as to maximize expected welfare:

$$
C^{*} \in \arg \max _{C} W(C),
$$

where for a given $C, W(C)$ is the expected welfare:

$$
W(C) \equiv \int_{R_{l}}^{R_{h}} \frac{1}{\Delta} \omega(C, R) d R,
$$

and the project welfare function $\omega(C, R)$ is as indicated in figure 3 :

$$
\omega(C, R) \equiv \begin{cases}R-1, & R>\max \left(\bar{B}+1-C-\zeta, R_{S}\right) \\ R-1-\frac{\phi}{2}, & R_{F}<R \leq \bar{B}+1-C-\zeta \\ 0, & R \leq \min \left(R_{S}, R_{F}\right)\end{cases}
$$

Straightforward calculations yield

$$
W(C)= \begin{cases}\frac{1}{2 \Delta}\left\{\left(R_{h}-1\right)^{2}-(\zeta-\bar{B}+C(1+2 \kappa))^{2}\right\}-\frac{\phi}{\Delta}(\bar{B}-\zeta-C(1+\kappa)), & C<C_{S}^{*} \\ \frac{1}{2 \Delta}\left\{\left(R_{h}-1\right)^{2}-(C \kappa)^{2}\right\}, & C \geq C_{S}^{*}\end{cases}
$$

where $C_{S}^{*}$ is defined in equation (8). 
To find $C^{*}$, note firstly that

$$
\lim _{C \uparrow C_{S}^{*}} W(C)=\lim _{C \downarrow C_{S}^{*}} W(C)=\frac{1}{2 \Delta}\left\{\left(R_{h}-1\right)^{2}-(C \kappa)^{2}\right\},
$$

so $W($.$) is a continuous function on \Re_{\geq 0}$. Moreover, $W($.$) is trivially decreasing for C>C_{S}^{*}$. This is intuitively as well as mathematically obvious: since banks are always sound when $C>\frac{\bar{B}-\zeta}{1+\kappa}$, increasing $C$ beyond $C_{S}^{*}$ serves simply to increase underinvestment.

For $C<C_{S}^{*}$ increasing $C$ has two effects. Firstly, the fragile region $\mathcal{F}$ within which the bank assumes systemic risk shrinks. This serves unambiguously to raise welfare. Secondly, the capital costs $C \kappa$ of investing and hence the hurdle rate FIR increase. This increases welfare provided $F I R<1$ so that risk shifting is causing overinvestment; conversely, it decreases welfare if $F I R>1$, in which case high capital costs are already causing underinvestment.

When $C<C_{S}^{*}, W^{\prime}(C)=0$ when $C=C_{F}^{*}$, defined in equation (7). Note that $C_{F}^{*}>0$ and that $C_{F}^{*}<C_{S}^{*}$ whenever $\phi<\bar{\phi}$, defined in equation (9): when this is the case, it follows because $W(C)$ is concave, continuous at $C_{S}^{*}$ and decreasing for $C>C_{S}^{*}$ that the regulator will set $C=C_{F}^{*}$. Expected welfare is then given by

$$
W_{F} \equiv W\left(C_{F}^{*}\right)=\frac{1}{2 \Delta}\left(R_{h}-1\right)^{2}-\frac{\phi}{2 \Delta(1+2 \kappa)^{2}}\left\{2(\bar{B}-\zeta) \kappa(1+2 \kappa)-\phi(1+\kappa)^{2}\right\}
$$

If $\phi>\bar{\phi}$ then $C_{F}^{*}>C_{S}^{*}: W(C)$ is then strictly increasing for $C<C_{S}^{*}$ and strictly decreasing for $C>C_{S}^{*}$. The regulator will therefore set $C=C_{S}^{*}$.

\section{Proof of Proposition 4}

The proof proceeds as follows. Firstly, we derive the expected profits of diversified and undiversified conglomerates as functions of $(C, R)$. Secondly, we identify $(C, R)$ values for which diversified conglomerates outperform undiversified conglomerates, and then we identify $(C, R)$ values for which playing safe dominates either strategy. Finally, we compare the manager's IR constraint for each region with its upper bound and so derive a feasible investment region.

Diversified Conglomerates. It is convenient to define the regions $\mathcal{F}_{1}, \mathcal{F}_{2}, \mathcal{F}_{3}, \mathcal{F}_{4}$, and $\mathcal{F}_{5}$ as follows:

$$
\begin{aligned}
& \mathcal{F}_{1}=\{(C, R): R<1-C\} \\
& \mathcal{F}_{2}=\{(C, R): 1-C \leq R<\min (2 \bar{B}+1-C, 1-C+\rho)\} \\
& \mathcal{F}_{3}=\{(C, R): 2 \bar{B}+1-C \leq R<1-C+\rho\} \\
& \mathcal{F}_{4}=\{(C, R): 1-C+\rho \leq R<\min (2 \bar{B}+(1-C), 1-C+\rho+2 \bar{B})\} \\
& \mathcal{F}_{5}=\{(C, R): \max (1-C+\rho, 2 \bar{B}+(1-C)) \leq R<1-C+\rho+2 \bar{B}\}
\end{aligned}
$$

The regions are illustrates in figure 6 . They divide the plane according to the expected deposit insurance payouts and the expected costs of charter value loss.

When $(C, R) \in \mathcal{F}_{1}$ the conglomerate fails in the middle and low states and in neither of these states will the bond-holders receive a payment. 


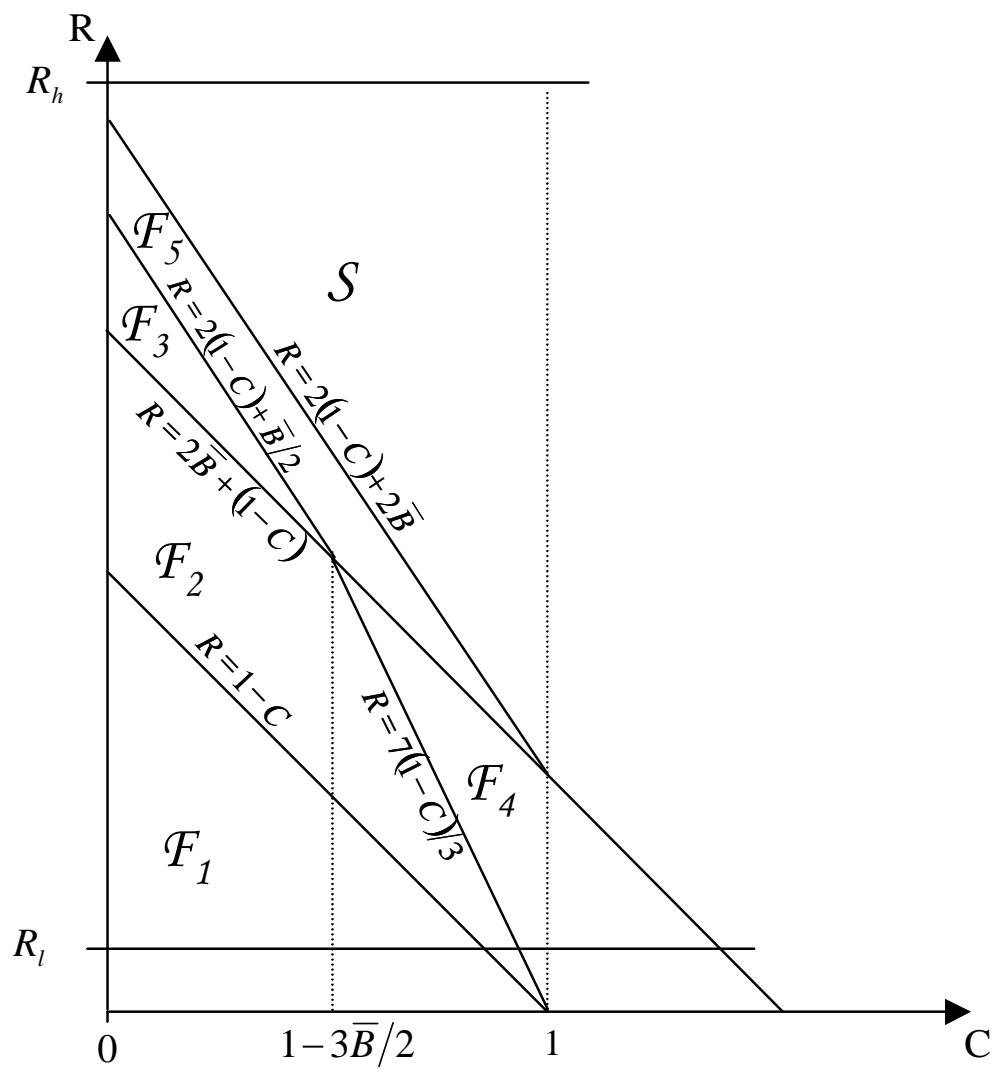

Figure 6: Fragile and sound regions in consolidated conglomerates with $\beta=2 \bar{B}$. Note that region $\mathcal{F}_{3}$ vanishes when $\bar{B} \geq \frac{2}{3}$.

When $(C, R) \in \mathcal{F}_{2}$ or $(C, R) \in \mathcal{F}_{4}$, the conglomerate fails in the low state and the bond-holders will in this case receive nothing so that the conglomerate receives a deposit insurance fund subsidy. The conglomerate fails in the middle state only when $(C, R) \in \mathcal{F}_{2}$, but in this case the bond-holders are partially repaid and so there is no deposit insurance payout. Hence regions $\mathcal{F}_{2}$ and $\mathcal{F}_{4}$ are distinguished only by the additional expected loss of charter value in region $\mathcal{F}_{2}$.

When $(C, R) \in \mathcal{F}_{3}$ or $(C, R) \in \mathcal{F}_{5}$, no default is so large that the bond holders receive no payment and hence the conglomerate never draws upon the deposit insurance fund. In both regions default occurs in the bottom state; in the middle state it occurs only in region $\mathcal{F}_{3}$. One again therefore the two regions are distinguished only by their respective expected charter values.

The expected profit of the conglomerate in region $\mathcal{F}_{1}$ is

$$
\pi_{F 1} \equiv\{R-2(1+C \kappa)\}-\frac{3}{4} \zeta+\left\{\frac{1}{2}(1-C-R)+\frac{1}{4}(1-C-R+2 \bar{B})\right\} .
$$

The first curly bracketed expression is the expected conglomerate profit in a world with perfect information and no externalities. The second term is the expected loss of charter value. The third is the expected value of the deposit insurance subsidy.

Similarly, the expected profits of the conglomerate in regions $\mathcal{F}_{2}, \mathcal{F}_{3}, \mathcal{F}_{4}$ and $\mathcal{F}_{5}$ are given by the following expressions: 


$$
\begin{aligned}
& \pi_{F 2} \equiv R-2(1+C \kappa)-\frac{3}{4} \zeta+\frac{1}{4}(1-C-R+2 \bar{B}) ; \\
& \pi_{F 3} \equiv R-2(1+C \kappa)-\frac{3}{4} \zeta ; \\
& \pi_{F 4} \equiv-2(1+C \kappa)-\frac{1}{4} \zeta+\frac{1}{4}(1-C-R+2 \bar{B}) ; \\
& \pi_{F 5} \equiv R-2(1+C \kappa)-\frac{1}{4} \zeta .
\end{aligned}
$$

Undiversified Conglomerates. Analogously with the diversified case, we define regions $\hat{\mathcal{F}}_{1}$ and $\hat{\mathcal{F}}_{2}$ as follows:

$$
\begin{aligned}
& \hat{\mathcal{F}}_{1} \equiv\{(C, R): R<\bar{B}+1-C\} \\
& \hat{\mathcal{F}}_{2} \equiv\{(C, R): \bar{B}+1-C \leq R<\bar{B}+1-C+\rho\}
\end{aligned}
$$

Regions $\hat{\mathcal{F}}_{1}$ and $\hat{\mathcal{F}}_{2}$ are illustrated in figure 7 .

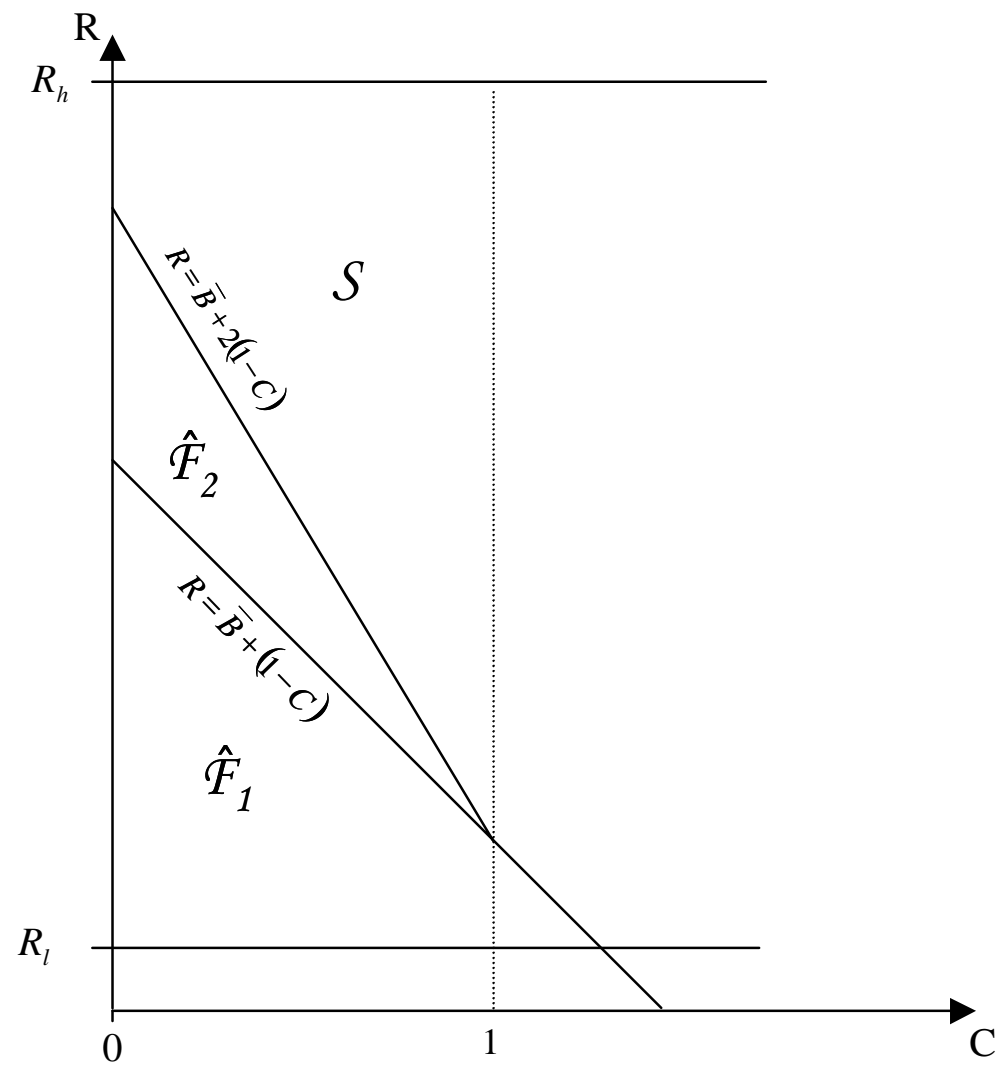

Figure 7: Fragile and sound regions in consolidated conglomerates with $\beta=\bar{B}$.

For $(C, R) \in \hat{\mathcal{F}}_{1}$ the bond-holders receive nothing if the conglomerate fails and hence the conglomerate receives a deposit insurance fund payout, while for $(C, R) \in \hat{\mathcal{F}}_{2}$ the bond-holders 
receive a payment in the event of conglomerate failure and there is therefore no deposit insurance payment.

The expected profits from running an undiversified conglomerate in regions $\hat{\mathcal{F}}_{1}$ and $\hat{\mathcal{F}}_{2}$ are as follows:

$$
\begin{aligned}
& \hat{\pi}_{F 1} \equiv R-2(1+C \kappa)-\frac{1}{2} \zeta+\frac{1}{2}(1-C-R+\bar{B}) ; \\
& \hat{\pi}_{F 2} \equiv R-2(1+C \kappa)-\frac{1}{2} \zeta .
\end{aligned}
$$

The first two terms in these expressions are again the expected profits in a world without agency effects; the term involving $\zeta$ is the expected charter value loss and the last term in the expression for $\hat{\pi}_{F 1}$ is the expected deposit insurance fund payout.

Lemma 4 (Choosing Between Diversified and Undiversified Conglomerates) The condition for an integrated conglomerate to prefer $\beta=2 \bar{B}$ to $\beta=\bar{B}$ depends upon the value of $(C, R)$ as follows:

1. In $\mathcal{F}_{1} \cap \hat{\mathcal{F}}_{1}=\{(C, R): R \leq 1-C\}$,

$$
\frac{1}{4}(1-C-R) \geq \frac{1}{4} \zeta
$$

2. In $\mathcal{F}_{2} \cap \hat{\mathcal{F}}_{1}=\left\{(C, R): 1-C<R \leq \min \left(1-C+\bar{B}, \frac{7}{3}(1-C)\right)\right\}$,

$$
\frac{1}{4} \zeta \leq \frac{1}{4}(R-(1-C))
$$

3. In $\mathcal{F}_{2} \cap \hat{\mathcal{F}}_{2}=\left\{(C, R): 1-C<R \leq \min \left(2 \bar{B}+(1-C), \frac{7}{3}(1-C)\right)\right\}$,

$$
-\frac{1}{4} \zeta \leq \frac{1}{4}(1-C-R+2 \bar{B})
$$

which is always true;

4. In $\mathcal{F}_{3} \cap \hat{\mathcal{F}}_{2}=\{(C, R): 1-C+\bar{B}<R \leq \bar{B}+2(1-C)\},-\frac{3}{4} \zeta \geq-\frac{1}{2} \zeta$, which is impossible;

5. In $\mathcal{F}_{4} \cap \hat{\mathcal{F}}_{1}=\left\{(C, R): \frac{7}{3}(1-C)<R \leq \bar{B}+(1-C)\right\}, \frac{1}{4} \zeta \geq \frac{1}{4}(1-C-R)$, which is always true;

6. In $\mathcal{F}_{4} \cap \hat{\mathcal{F}}_{2}=\{(C, R): \bar{B}+(1-C) \leq R<2 \bar{B}+(1-C)\}, \frac{1}{4}(1-C-R+2 \bar{B})-\frac{1}{4} \zeta \geq-\frac{1}{2} \zeta$, which is always true;

7. In $\mathcal{F}_{5} \cap \hat{\mathcal{F}}_{2}=\{(C, R): \bar{B}+(1-C) \leq R<2 \bar{B}+(1-C)\},-\frac{\zeta}{4}>-\frac{1}{2} \zeta$, which is always true.

Proof. Trivial by manipulation of the expressions for $\pi_{F}$ and $\hat{\pi}_{F}$.

The intuition for this result is simple. When $(C, R) \in \mathcal{F}_{1}$, playing risky with two projects increases the deposit insurance payout at the expense of greater expected charter value loss. This is desirable only for sufficiently low $\zeta$.

When $(C, R) \in \mathcal{F}_{1} \cap \hat{\mathcal{F}}_{1}$ the conglomerate receives a large deposit insurance payout with probability $\frac{1}{4}$ if $\beta=2 \bar{B}$. Setting $\beta=\bar{B}$ yields a smaller deposit insurance payout with probability $\frac{1}{2}$. The latter option is preferable for the former for sufficiently low $R$; for $R$ higher the latter option 
yields a better return in exchange for the expected drop in charter value. If instead $(C, R) \in \hat{\mathcal{F}}_{2}$, setting $\beta=\bar{B}$ never generates a payout from the deposit insurance fund. In this the conglomerate will clearly prefer to set $\beta=2 \bar{B}$.

When $(C, R) \in \mathcal{F}_{3} \cap \hat{\mathcal{F}}_{2}$, no value of $\beta$ will generate a deposit insurance fund payment. The conglomerate therefore prefers the value which minimizes expected charter value losses: in other words, it sets $\beta=\bar{B}$.

When $(C, R) \in \mathcal{F}_{4} \cap \hat{\mathcal{F}}_{1}$, the expected reduction in charter value with $\beta=2 \bar{B}$ are unambiguously lower than with $\beta=\bar{B}$. Moreover, the deposit insurance subsidy is larger.

When $(C, R) \in \hat{\mathcal{F}}_{2}$ there is no deposit insurance subsidy; the expected charter value losses in $\mathcal{F}_{2}$ and $\mathcal{F}_{5}$ are lower for $\beta=2 \bar{B}$ than for $\beta=\bar{B}$ and the conglomerate will therefore elect to play risky with two projects in $\left(\mathcal{F}_{4} \cap \hat{\mathcal{F}}_{2}\right) \cup\left(\mathcal{F}_{5} \cap \hat{\mathcal{F}}_{2}\right)$.

Lemma 5 (The Decision to Take Risks) Running a sound conglomerate dominates running either a diversified or an undiversified conglomerate precisely when condition (12) is satisfied:

$$
\left.\begin{array}{c}
(R<7(1-C) / 3) \text { and }(R>1-C+2 \bar{B}-3 \zeta) ; \\
\text { OR } \\
(R>7(1-C) / 3) \text { and }(R>1-C+2 \bar{B}-\zeta) .
\end{array}\right\}
$$

Proof. Note that there is no value to risk-taking when the consequential deposit insurance payout will be zero. This is the case for undiversified conglomerates when $(C, R) \in \hat{\mathcal{F}}_{2}$, and for diversified conglomerates when $(C, R) \in \mathcal{F}_{3} \cup \mathcal{F}_{5}$. Hence if $(C, R) \in\left(\hat{\mathcal{F}}_{2} \cap \mathcal{F}_{3}\right) \cup\left(\hat{\mathcal{F}}_{2} \cap \mathcal{F}_{5}\right)$, running a sound conglomerate dominates either form of fragile conglomerate.

It remains to check when sound conglomerates are preferred in regions $\mathcal{F}_{1}, \mathcal{F}_{2}$ and $\mathcal{F}_{4}$. In $\mathcal{F}_{1}$ it is easy to show that a sufficient condition for fragile conglomerates always to dominate sound ones is

$$
1-C-R+\bar{B}>\zeta
$$

We expect $\zeta$ to be small relative to the total losses $\bar{B}$ from failure and we therefore assume that this is the case. Finally, condition (12) follows from straightforward comparison of the expressions for $\pi_{F 2}, \pi_{F 4}$ to the expected profits $R-2(1+C \kappa)$ from running a sound conglomerate.

Lemma 6 Consider an integrated conglomerate with capital requirement $C$ and define $\beta$ as in equation (10) to be its total level of risk. If condition (12) of lemma 5 is satisfied then $\beta=0$; if condition (13) is satisfied then $\beta=\bar{B}$; otherwise, $\beta=2 \bar{B}$.

$$
(1-C-\zeta<R<1-C+\zeta) \text { and }(R<7(1-C) / 3) .
$$

Proof. The lemma follows immediately from lemmas 4 and 5

Lemma 6 partitions the $(C, R)$ space into five regions as illustrated in figure 8 , according to whether an integrated conglomerate with two projects returns the highest expected return when diversified $(\beta=2 \bar{B})$, undiversified $(\beta=\bar{B})$, or safe $(\beta=0)$. We now investigate the manager's individual rationality constraints in each of these regions. 


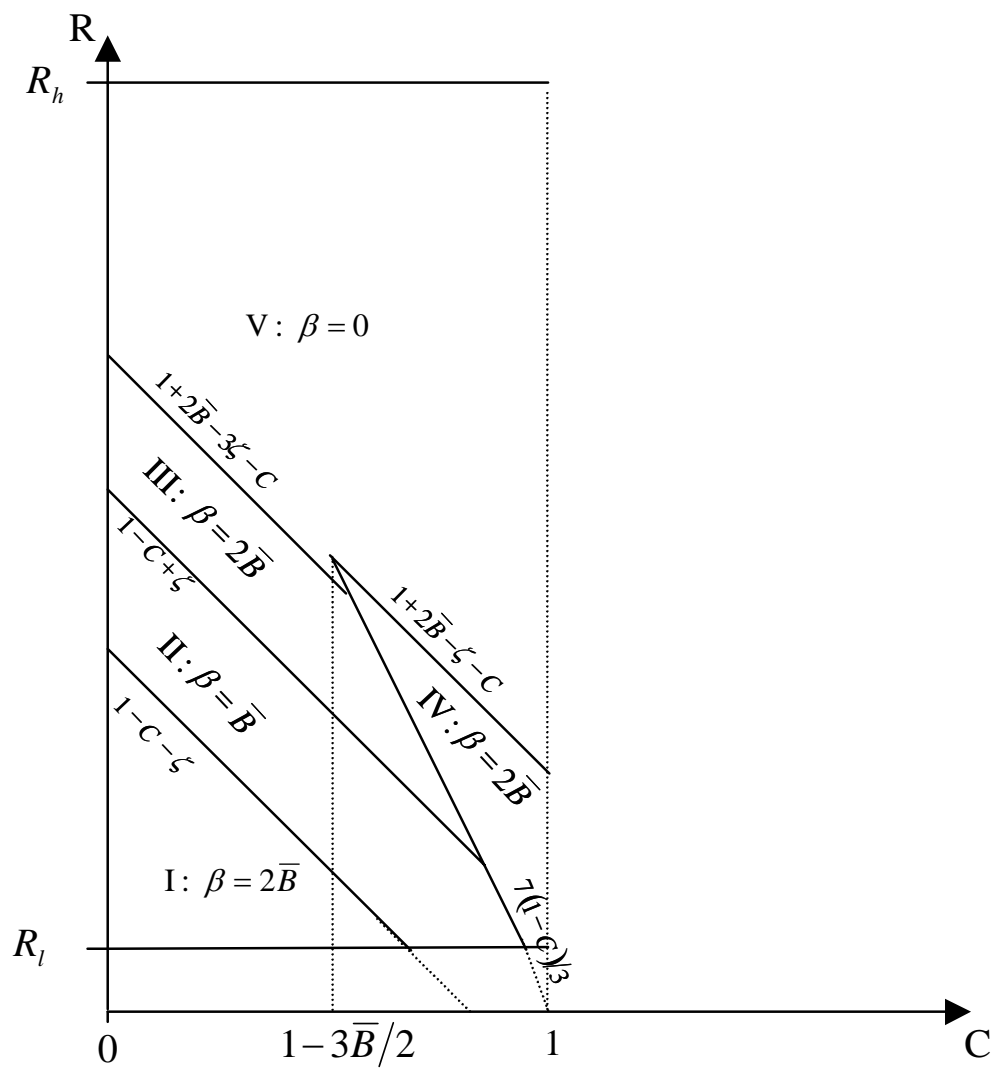

Figure 8: Preferred risk levels for a two project consolidated conglomerate.

Lemma 7 (Manager's Participation Constraints) In an integrated conglomerate with two projects,

1. The manager's IR constraint is violated whenever $(C, R)$ lies in region I or II;

2. The manager's IR constraint can be satisfied in region III if and only if

$$
\bar{B}>\frac{1}{2}(1+C+3 \zeta+2 C \kappa) ;
$$

3. The manager's IR constraint can be satisfied in region IV if and only if

$$
\bar{B}>\frac{1}{2}(1+C+\zeta+2 C \kappa) .
$$

Proof. Setting $\pi_{F 1}$ and $\hat{\pi}_{F 1}$ greater than or equal to zero yields the respective IR constraints for regions I and II: $R \geq R_{F 1} \equiv 5-2 B+3 C+3 \zeta+8 C \kappa$ and $R \geq R_{\hat{F} 1} \equiv 3-B+C+\zeta+4 C \kappa$. The manager's IR constraint can be satisfied in region I iff $R_{F 1} \leq 1-C-\zeta$ iff $B>2(1+C+\zeta+2 C \kappa)$, which is impossible since $B<1$. Similarly, the IR constraint is satisfiable in region II iff $R_{\hat{F} 1} \leq$ $1-C+\zeta$ iff $B>2(1+C)+4 C \kappa$, which is again impossible. The IR constraint in region III is obtained by setting $\pi_{F 2} \geq 0: R \geq R_{F 2} \equiv \frac{1}{3}(7-2 B+C+3 \zeta+8 C \kappa)$. It can be satisfied in region III iff $R_{F 2} \leq 1+2 \bar{B}-3 \zeta-C$ from which condition (14) follows immediately. In region IV the 
IR constraint is obtained from $\pi_{4}: R \geq R_{F 4} \equiv \frac{1}{3}(7-2 B+C+\zeta+8 C \zeta)$. It can be satisfied iff $R_{F 4} \leq 1+2 \bar{B}-\zeta-C$ which yields condition (15).

This concludes the proof of proposition 4 .

Proof of Lemma 1

Inserting $C=\frac{1}{2} C_{S}^{*}$ into equations (14) and (28) yields equations 16) and (17).

$$
\begin{aligned}
& \bar{B}>\frac{2}{3}+\frac{5}{3} \zeta \\
& \bar{B}>\frac{2}{3}+\zeta .
\end{aligned}
$$

The relevant IR constraint is $R_{F 2}$ precisely when $\frac{1}{2} C_{S}^{*}<\frac{2 \bar{B}-3 \zeta}{8(1+\kappa)}$, or $\bar{B}<\frac{\zeta}{2}(1-\kappa)$, which contradicts condition (16). The IR constraint is $R_{F 4}$ iff $\bar{B}>\frac{\zeta}{2}(3+2 \kappa)$, which is implied by condition (17).

\section{Proof of Lemma 2}

The expected profit of a single project integrated conglomerate with return $R$ is given by $\hat{\pi}_{F 1}(C, R)$, $\hat{\pi}_{F 2}(C, R)$ or $\pi_{S}$ according to whether $(C, R)$ lies in region $\mathcal{F}_{1}, \mathcal{F}_{2}$, or $\mathcal{S}$ of figure 7 . It is easy to check that profit is monotonically increasing in $R$. Accepting a second positive NPV project without risk is equivalent to increasing the expected return on the first project: since taking risk is optional the second project will be accepted. The proof that the firm accepts some negative NPV projects appears in the text. 


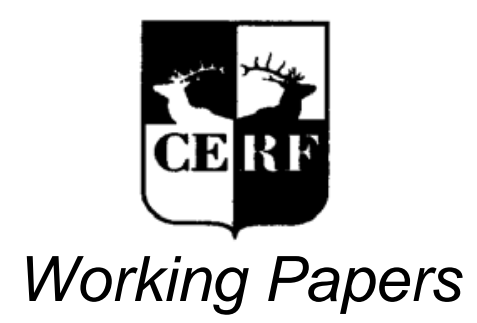

\begin{tabular}{|c|c|c|c|}
\hline No & Published & & Title \\
\hline 1 & May & 2002 & On Strategic Default and Liquidity Risk \\
\hline 2 & June & 2002 & The Supervisory Approach: A Critique \\
\hline 3 & August & 2002 & $\begin{array}{l}\text { Depreciation Bias, Financial-Sector Fragility and Currency } \\
\text { Risk }\end{array}$ \\
\hline 4 & December & 2002 & $\begin{array}{l}\text { The New Basel Accord and Developing Countries: } \\
\text { Problems and Alternatives }\end{array}$ \\
\hline 6 & January & 2003 & $\begin{array}{l}\text { Economic Slowdown in the U.S., - The Revitalisation of } \\
\text { Fiscal Policy and the Case for a Co-Ordinated Global } \\
\text { Reflation }\end{array}$ \\
\hline 7 & December & 2003 & $\begin{array}{l}\text { Establishing a European Securities Regulator: Is the } \\
\text { European Union an Optimal Economic Area for a Single } \\
\text { Securities Regulator? }\end{array}$ \\
\hline 8 & October & 2003 & $\begin{array}{l}\text { Empirical Modeeling of Contagion: A Review of } \\
\text { Methodologies }\end{array}$ \\
\hline 9 & October & 2003 & International Financial Contagion: What Do We Know? \\
\hline 10 & November & 2003 & $\begin{array}{l}\text { Two-Country Stock-Flow-Consistent Macroeconomics } \\
\text { Using a Closed Model Within a Dollar Exchange Regime }\end{array}$ \\
\hline 11 & November & 2003 & $\begin{array}{l}\text { Testing for Changing Persistence in U.S. Treasury } \\
\text { On/Off Spreads Under Weighted-Symmetric Estimation }\end{array}$ \\
\hline 12 & February & 2004 & $\begin{array}{l}\text { Features of a Realistic Banking System Within a Post- } \\
\text { Keynesian Stock-flow Consistent Model }\end{array}$ \\
\hline 13 & February & 2004 & Credit-Risk Transfer and Financial Sector Performance \\
\hline 14 & March & 2004 & $\begin{array}{l}\text { Finance and Technical Change: A Neo-Schumpeterian } \\
\text { Perspective }\end{array}$ \\
\hline 15 & April & 2004 & $\begin{array}{l}\text { Simple Open Economy Macro with Comprehensive } \\
\text { Accounting - A Radical Alternative to the Mundell } \\
\text { Fleming Model }\end{array}$ \\
\hline 16 & May & 2004 & $\begin{array}{l}\text { Towards a Reconstruction of Macroeconomics Using a } \\
\text { Stock Flow Consistent (SFC) Model }\end{array}$ \\
\hline 17 & July & 2004 & $\begin{array}{l}\text { Corporate Governance and Bank Regulation: The } \\
\text { Regulator as Stakeholder }\end{array}$ \\
\hline 18 & January & 2005 & $\begin{array}{l}\text { Credit Derivatives, the Liquidity of Bank Assets, and } \\
\text { Banking Stability }\end{array}$ \\
\hline 19 & March & 2005 & Regulating Financial Conglomerates \\
\hline
\end{tabular}

Author(s)

Demosthenes N. Tambakis

Jonathan Ward

Demosthenes N. Tambakis

Jonathan Ward

Alex Izurieta

Kern Alexander

Mardi Dungey, Renée Fry, Brenda González-Hermosillo \& Vance L. Martin Mardi Dungey \& Demosthenes N. Tambakis

Wynne Godley \& Marc Lavoie

L. Vanessa Smith \& Demosthenes N.

Tambakis

Wynne Godley \& Marc Lavoie

Wolf Wagner and Ian Marsh

Carlota Perez

Wynne Godley \& Marc Lavoie

Wynne Godley

Kern Alexander

Wolf Wagner

Xavier Freixas, Gyongyi Loranth, Alan D. Morrison

Please address enquiries about the series to:

The Administrator, Cambridge Endowment for Research in Finance, Judge Institute of Management, Trumpington Street, Cambridge CB2 1AG, UK, Tel: +44(0) 1223764 115, E-Mail: admin@cerf.cam.ac.uk, http://www.cerf.cam.ac.uk 